\title{
NBSIR 88-3765
}

All102 854201

\section{Effect of Blow Count on Energy Transfer in SPT}

Felix Y. Yokel

U.S. DEPARTMENT OF COMMERCE

National Bureau of Standards

National Engineering Laboratory

Center for Building Technology

Gaithersburg, MD 20899

July 1988
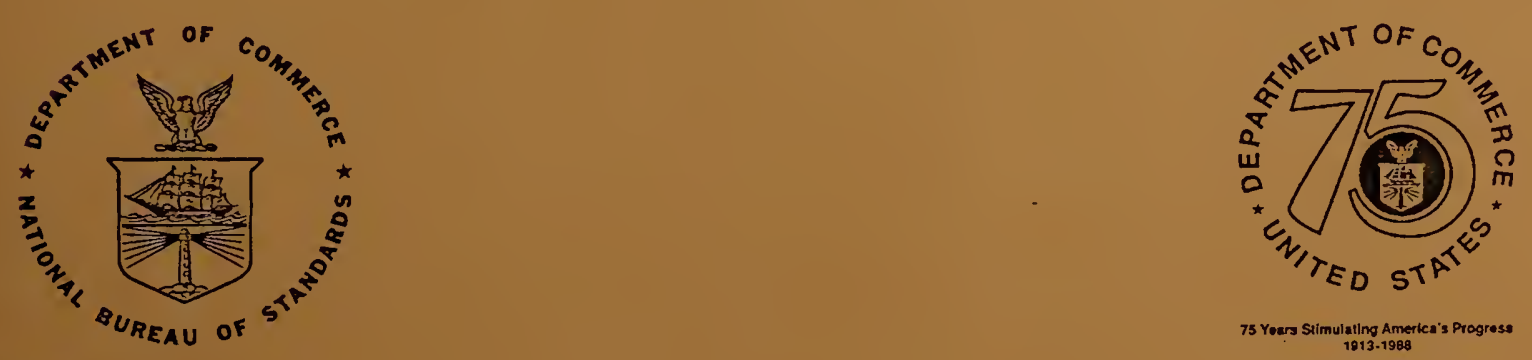

75 Yoess Stimulating America's Progrese
1013.1986 



\section{TRANSFER IN SPT}

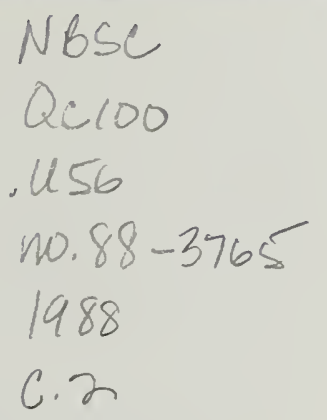

Felix Y. Yokel

U.S. DEPARTMENT OF COMMERCE

National Bureau of Standards

National Engineering Laboratory

Center for Building Technology

Gaithersburg, MD 20899

July 1988

U.S. DEPARTMENT OF COMMERCE, C. William Verity, Secretary NATIONAL BUREAU OF STANDARDS, Ernest Ambler, Director 



\section{ABSTRACT}

A rigid-hammer model is used to investigate the effect of the blow count in Standard Penetration Tests on the energy transmission characteristics of the tests. It is shown that the percentage of the impact energy used to advance the sampler decreases with an increase in blow count and could increase somewhat with increasing drill rod size, and that for low blow counts several penetration cycles are required to transmit the energy to the sampler. The effect of the blow count on the energy loss associated with short drill rod lengths is also investigated. It is shown that the energy loss associated with the short-rod effect is less than that predicted when total energy rather than useable energy is considered, and that the energy loss decreases with an increase in blow count.

Keywords: Boring; energy transfer; field tests; in-situ testing; soil sampling; Standard Penetration Test; wave equation. 
NOTATION

The following symbols are used in this paper.
$\mathrm{a}=$
cross section area of drill rod in $\mathrm{m}^{2}$
$c=$
stress wave propagation velocity in steel in $\mathrm{m} / \mathrm{s}$
$E_{\mathrm{rl}}=$
energy transfered to a long rod in $\mathrm{N}-\mathrm{m}$
$E_{p}=$
$\mathrm{E}_{\mathrm{S}}=$
$\mathrm{E}_{\mathrm{rS}}=$
$E R_{\mathrm{p}}=$
$E R_{S}=$
$\mathrm{F}_{\mathrm{rd}}=$
energy used for sampler penetration in $\mathrm{N}-\mathrm{m}$
energy used for sampler displacement in $\mathrm{N}-\mathrm{m}$
energy transfered to a short rod in $\mathrm{N}-\mathrm{m}$
energy fraction used for sampler penetration
energy fraction used for total sampler displacement
force transmitted through rod by downward moving stress wave in $\mathrm{N}$
$F_{r u}=$
force transmitted through rod by upward moving stress wave in $\mathrm{N}$
$F_{S}=$ force exerted by soil on sampler in $\mathrm{N}$
$\ell=$ length of drill rod in $\mathrm{m}$
$\mathrm{M}_{\mathrm{h}}=\quad$ mass of hammer in $\mathrm{Kg}$
$\mathrm{N}=$ blow count in SPT in blows/ft (blows/.3048m)
$\mathrm{s}=$ distance of sampler penetration in $\mathrm{m}$
$t=$ time in $s$
$t *=$
time at which soil penetration ceases in $s$
$v_{0}^{\prime}=$ impact velocity of hammer in $\mathrm{m} / \mathrm{s}$
$v_{0}=$
$\mathrm{v}=$
effect of $v_{0}$ ' below anvil in $\mathrm{m} / \mathrm{s}$
$\delta=$
particle velocity in $\mathrm{m} / \mathrm{s}$
$\rho=$
elastic soil compression in $\mathrm{mm}$

\section{Subscripts}

$\mathrm{d}=$

$(n)=$

$\mathrm{p}=$

$\mathrm{u}=$

downward direction

penetration cycle number

subscript for soil penetration (velocity)

upward direction 
INTRODUCTION

Part of the energy transmitted in the Standard Penetration Test (SPT) from the hammer to the drill rod advances the sampler into the soil, and thus is responsible for the "blow count" (N). Another part of the energy remains in the drill rod as strain energy of deformation and kinetic energy associated with the travelling stress wave and does not contribute to the penetration of the sampler into the soil. A rigid-hammer model is used to study the effect of the blow count on the energy transfer mechanism, the efficiency of energy transmission, and the time required for energy transfer. The model has been previously used to study drill rod length effects (4), and it has been demonstrated in that case that the simplifying assumptions associated with the rigid hammer model did not significantly affect the results. The model does not deal with energy losses associated with the hammer/anvil geometry, nor does it consider energy loss by damping in the drill rod, for which no data are presently available.

FORCES AND PARTICLE VELOCITIES IN THE DRILL ROD

It has been shown (3) that a compressive-stress wave, imparted to a fixed-ended prismatic rod is reflected from the fixed end, where the stress is twice the stress of the arriving stress wave. The presence of the reaction force needed to reflect the compressive-stress wave is a necessary and sufficient condition for end fixity. Therefore, the drill rod in the SPT will act like a "fixed ended" rod from the instant when the force 
imparted to the sampler by the arriving stress wave is one-half the force required to advance the sampler into the soil. The energy of the stress wave arriving at the sampler after this instant does not contribute to further sampler penetration. Thus, the amount of energy which is used to advance the sampler decreases with increasing soil resistance.

At the instant sampler penetration ceases:

$$
\mathrm{F}_{\mathrm{S}}=2 \mathrm{~F}_{\mathrm{rd}}
$$

in which: $F_{S}=$ Force exerted by the soil on the sampler, and

$F_{r d}=$ Force transmitted to the sampler by the arriving stress wave.

The time variation of the force arriving at the sampler is (4):

$$
F_{r d}(t)=a v_{0}{ }^{\prime} c \rho \exp \left[\left(-a c p / M_{h}\right) t\right]
$$

in which: $M h=$ mass of hammer $(63.5 \mathrm{~kg}$ standard $)$

$\mathrm{v}_{\mathrm{O}}{ }^{\prime}=$ hammer impact velocity

$\mathrm{a}$ = hammer contact area (assumed equal to cross section area of rod)

c = stress wave propagation velocity ["bar velocity" (3) ] in steel=5047m/s

$\rho=$ mass density of steel $=7850 \mathrm{~kg} / \mathrm{m} 3$

$t=$ time elapsed from the arrival of the front of the stress wave at the sampler

The resultant force $F(t)$ acting on any cross section of the drill rod at any given instance is:

$$
F(t)=F_{r d}+F_{r u}
$$

in which: $F_{r d}=$ the force attributable to a downward moving stress wave

$$
\mathrm{F}_{\mathrm{ru}}=\text { the force attributable to an upward moving }
$$
(reflected) stress wave

The particle velocity in the drill rod at any cross section can be calculated from the forces attributable to the downward and upward moving stress waves as follows (3):

$$
\mathrm{v}=\mathrm{v}_{\mathrm{d}}-\mathrm{v}_{\mathrm{u}}=(1 / \mathrm{ac} \rho)\left(\mathrm{F}_{\mathrm{rd}}-\mathrm{F}_{\mathrm{ru}}\right)
$$


in which: $\mathrm{v}=$ resultant particle velocity

$v_{d}$ and $v_{u}$ are particle velocities that would result if $F_{\text {rd }}$ or $F_{\text {ru }}$ respectively were acting alone.

In equations 3 and 4 compressive stresses and downward particle velocities are taken as positive, tensile stresses and upward particle velocities are taken as negative.

\section{ENERGY AVAILABLE FOR SOIL PENETRATION}

If it is assumed that before the onset of sampler penetration the soil compresses elastically and that during sampler penetration the soil deformation is plastic and thus the force exerted by the soil on the sampler is reasonably uniform (an elasto-plastic model), then:

$$
F_{S}=1 / s\left(E_{S}-F_{S} \delta / 2\right)
$$

in which: $E_{S}=$ Total energy used to advance the sampler (including elastically stored energy), $\mathbf{s}=$ Distance of sampler penetration, and $\delta=$ Downward displacement of the sampler caused by elastic soil compression prior to penetration.

If a rigid-plastic model for soil resistance is used (the elastic soil deformation prior to sampler penetration is assumed to be zero) the energy used for sampler penetration can be calculated as follows:

At the sampler, the soil resistance during the penetration must be $F_{S}$. To maintain this reaction force, a force equal to $F_{S^{-}}$ $F_{r d}$ is reflected from the end of the rod and propagates upward. If $F_{S}-F_{r d}$ is negative this latter force is a tensile force. Thus at the sampler:

$$
\begin{aligned}
v_{p}= & v_{d}-v_{u}=(1 / a c p)\left[F_{r d}-\left(F_{s}-F_{r d}\right)\right]=(1 / a c p)\left(2 F_{r d}-F_{s}\right) \ldots(6) \\
& \text { in which: } v_{p}=\text { velocity of soil penetration. }
\end{aligned}
$$

As noted above, soil penetration will continue until $F_{S}=2 F_{r d}$. The time from the arrival of the compression wave at the sampler 
at which this condition occurs is designated as time $t^{*}$. After time $t *$ penetration will cease (or cease temporarily as explained later). Thus the energy used for sampler penetration,

$$
E_{S}=\int_{0}^{t^{*}} F_{S} v_{p} d t=-\frac{F_{S}}{a c p} \int_{0}^{t^{*}}\left\{2 a v_{O} c p \exp \left[-\left(a c p / M_{h}\right) t\right]-F_{s}\right\} d t=
$$

$$
=F_{S} / \operatorname{acp}\left\{2 M_{h v_{O}}\left[1-\exp \left(-\operatorname{acpt} * / M_{h}\right)\right]-F_{S} t^{*}\right\}
$$

in which:

$$
\begin{aligned}
& t^{*}=\left(M_{h} / \operatorname{acp}\right)\left[\ln \left(2 F_{O} / F_{S}\right)\right] \text { [from (1) and (2)] } \\
& F_{O}=a v_{O} c p \\
& v_{O} \text { is } v_{O}^{\prime} \text { adjusted for the anvil effect. } \\
& F_{S}=2 F_{r d}=2 a v_{O} c p e x p\left(-\operatorname{acpt} / M_{h}\right)
\end{aligned}
$$

Equation 7 accounts for the part of the energy contained in the initial downward moving stress wave which is utilized for soil penetration and thus dissipated. The rest of the energy is contained in the stress wave reflected upward from the end of the drill rod. The magnitude of this reflected stress at any time is: $F_{\text {ru }}=F_{S}-F_{r d}$. If this quantity is negative, the reflected stress $\left(F_{r u}\right)$ is tensile. This tensile stress propagates to the top of the rod, and if the arriving tensile stress exceeds the stress exerted by the hammer on the upper end of the drill rod it separates the rod from the hammer (this would be the case for the range of rod lengths and blow counts which are of practical interest). After hammer separation, the resulting reaction force at the top of the drill rod is zero, and therefore the upward moving stress wave is reflected and propagated down as a stress wave of equal magnitude and opposite sign. Thus the tensile stress wave initially reflected from the sampler returns to the sampler as a compressive-stress wave. This second cycle of compressive stress will further advance the sampler if the compressive stress propagated downward exceeds $\mathrm{F}_{\mathrm{S}} / 2$. If the soil resistance is low (the blowcount is low), there are several penetration cycles until the entire energy available for soil penetration has been utilized. 
In each successive increment of sampler advance the force in the compressive-stress wave arriving at the sampler is reduced by $\mathrm{F}_{\mathrm{S}}$. The following equations can be written for the energy utilized in any one penetration cycle:

$$
\begin{aligned}
E_{S}(n)=F_{S} / \operatorname{ac} \rho\{2 & \left.M_{h_{0} v_{O}}\left[1-\exp \left(-\operatorname{ac} \rho t_{(n)} / M_{h}\right)\right]-F_{S}(2 n-1) t(n)\right\} \\
t_{(n)} & =\left(M_{h} / \operatorname{ac} \rho\right)\left[\ln \left(F_{O} / F_{(n)}\right)\right] \\
F_{(n)} & =F_{S}(n-0.5)
\end{aligned}
$$

in which: $t(n)=$ the time elapsed between the arrival of the reflected compressive stress wave at the sampler and the cessation of sampler penetration in the nth penetration cycle. In the first $(n=1)$ penetration cycle $t(n)=t^{*}$.

The advance of the sampler in each penetration cycle, $s(n)$, can also be calculated. For the rigid-plastic model examined:

$$
S_{(n)}=E_{S(n)} / F_{S}=1 / \operatorname{acp}\left\{2 M_{h} v_{0}\left[1-\exp \left(-\operatorname{acpt}(n) / M_{h}\right)\right]-F_{S}(2 n-1) t(n)\right\}
$$

The total advance of the sampler per blow, $s$, and the blow count, $N$, are calculated as follows:

n

$$
s=\sum_{n=1} s(n) \ldots(12) ; \quad N=0.3048(m) / s
$$

The energy efficiency of the soil penetration, which is the percentage of the energy passing through the rod below the anvil actually used to advance the sampler, can be calculated as follows:

$$
E R_{S}=\left(\sum_{n=1}^{n} E_{S(n)}\right) / E_{\text {thru }}
$$

in which $E_{\text {thru }}$ is the energy passing through the rod below the anvil. The fraction of the potential energy of the hammer utilized for soil penetration can similarly be calculated if the energy loss in the hammer/anvil system is known. 
BLOW COUNT VS. SOIL RESISTANCE AND ENERGY EFFICIENCY

The relationship between the blow count (N) and the soil resistance, $F_{S}$, and the fraction of $E_{t h r u}$ used for soil penetration, $\mathrm{ER}_{\mathrm{S}}$, were calculated for a rigid-plastic soil penetration model and an $A$, as well as an NW rod. The following quantities were used in the calculations, in addition to those noted in Eq. (2):

Drill rods: $\begin{aligned} & A \text { rod } \\ & \text { NW rod a }=5.97 \mathrm{~kg} / \mathrm{m}\end{aligned}$

$\begin{array}{ll}\text { Energy/velocity: } & E_{\text {thru }}=0.64 \mathrm{E} \text { (free fall) }=304.2 \mathrm{~N}-\mathrm{m} \\ & v_{0}=0.8 \mathrm{v} \text { (free fall) }=3.095 \mathrm{~m} / \mathrm{s}\end{array}$

Force in drill rod: A rod $F_{0}=93,261 \mathrm{~N}$

$\mathrm{NW}$ rod $\mathrm{F}_{\mathrm{O}}^{\mathrm{O}}=127,785 \mathrm{~N}$

The results of the calculation are shown in figures 1 through 4. Figure $I$ shows plots of $F_{r d}(t)$ for the $A$ and $N W$ rods. The plots were calculated for a rigid-hammer model using Eq(2). Note that the initial force in the $N W$ rod is larger than that in the A rod. Because the total energy is the same for both rods, the force in the NW rod decays faster with time than that in the $A$ rod.

Figure 2 shows a plot of $E$ as a function of the blow count, $N$, calculated for an $A$ rod and a rigid-plastic soil resistance function. $E_{\mathrm{S}}$ is given as a percentage of $E_{t h r u}$. The upper curve in figure 2 shows the total percentage of energy utilized for soil penetration. It is obvious that the energy utilized decreases with increasing blow counts, because the force in the downward moving compression wave at which penetration ceases increases with the blow count. The dashed curves in the figure show the cumulative percentage of energy utilized in successive penetration cycles. Note that the energy utilized in the first cycle reaches a maximum at an approximate blow count of 60 . At this blow count the energy content of the reflected stress wave is the least. At smaller blow counts the amount of energy 


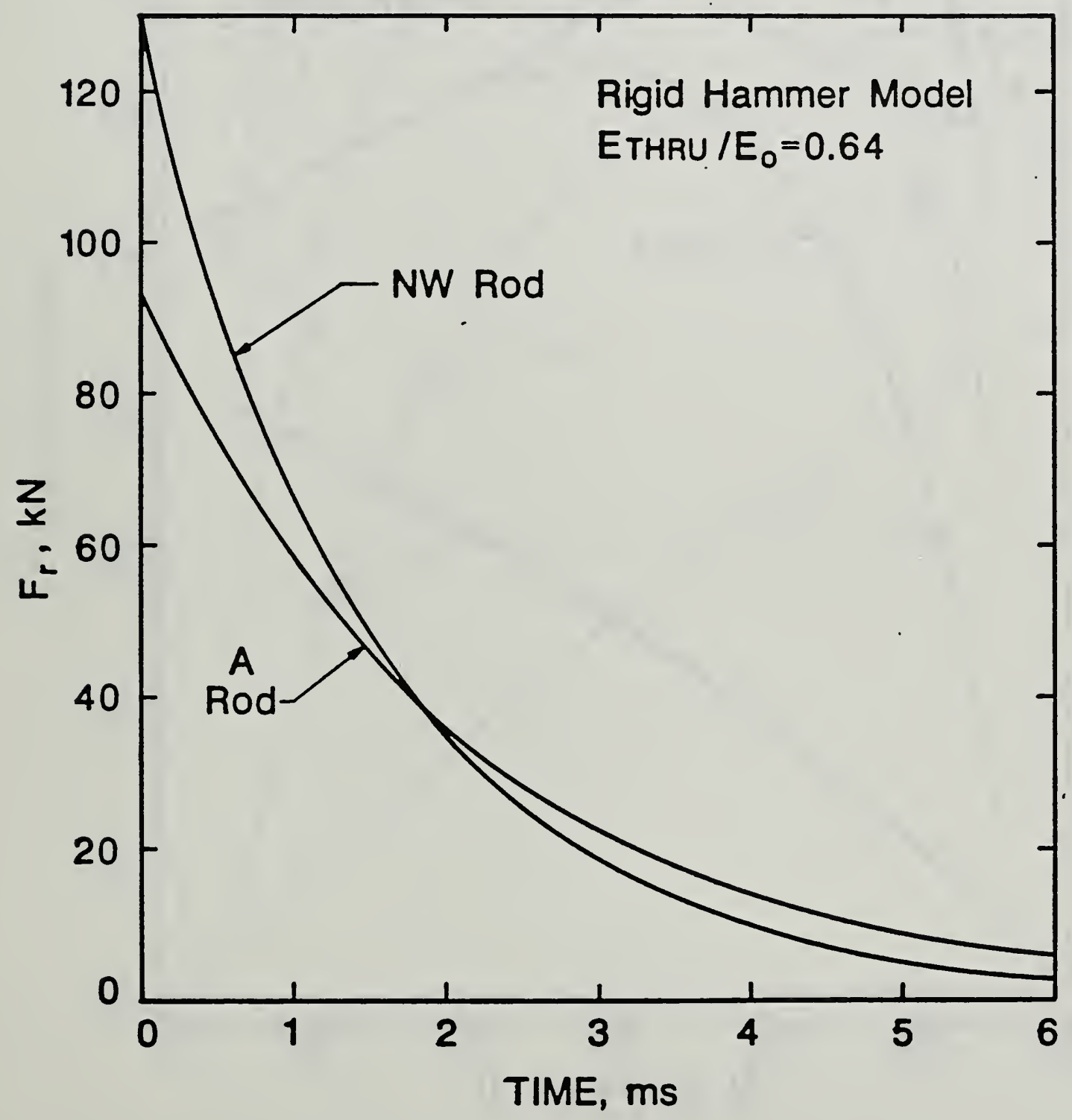

Figure 1: Force propagated down in the drill rod as a function of time for $A$ and $N W$ rods. 


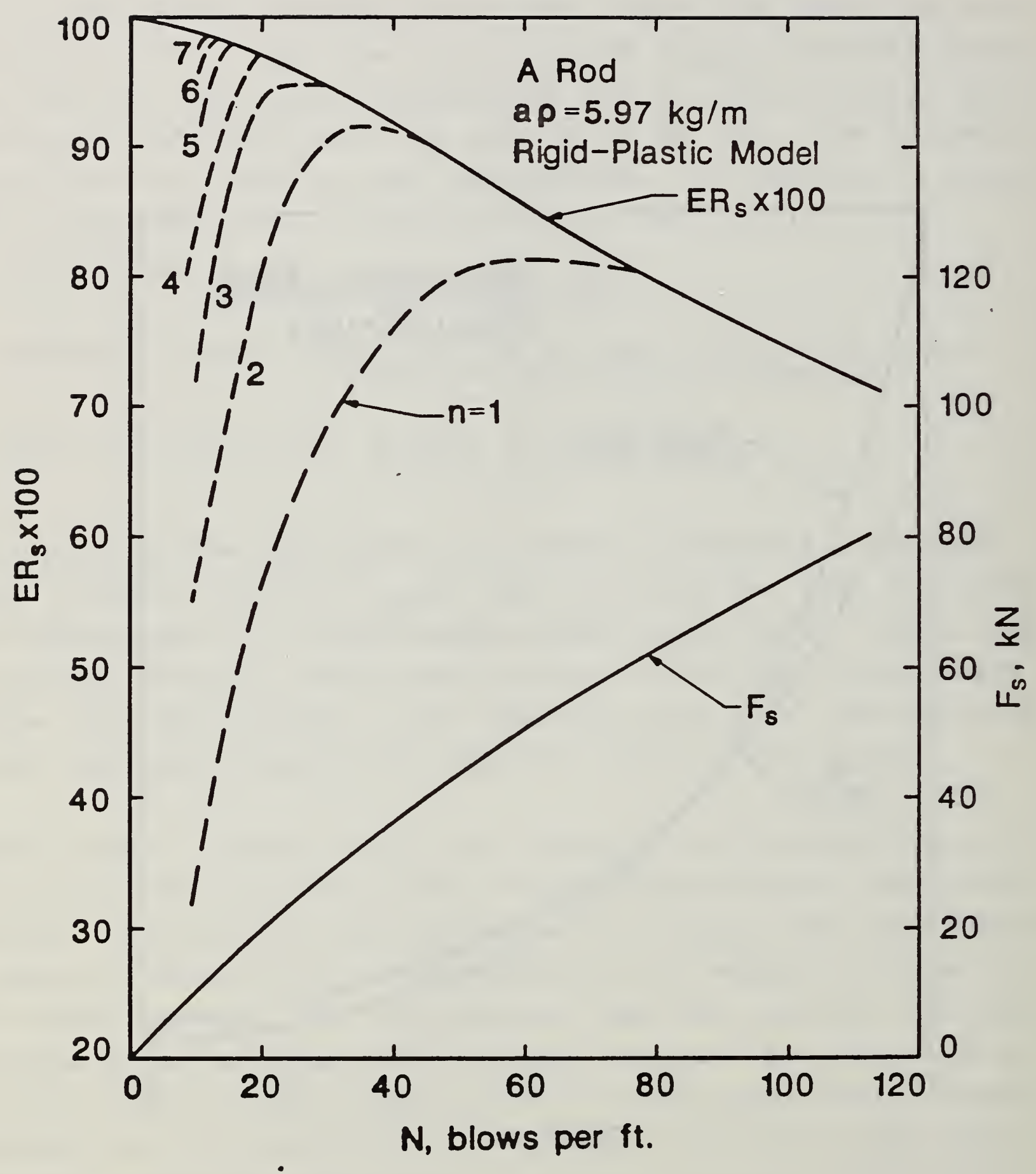

Figure 2: Energy Fraction Used For Soil Penetration as a Function of Blow Count Calculated For a Rigid Plastic Soil Resistance Function and an $A$ rod (no damping). 


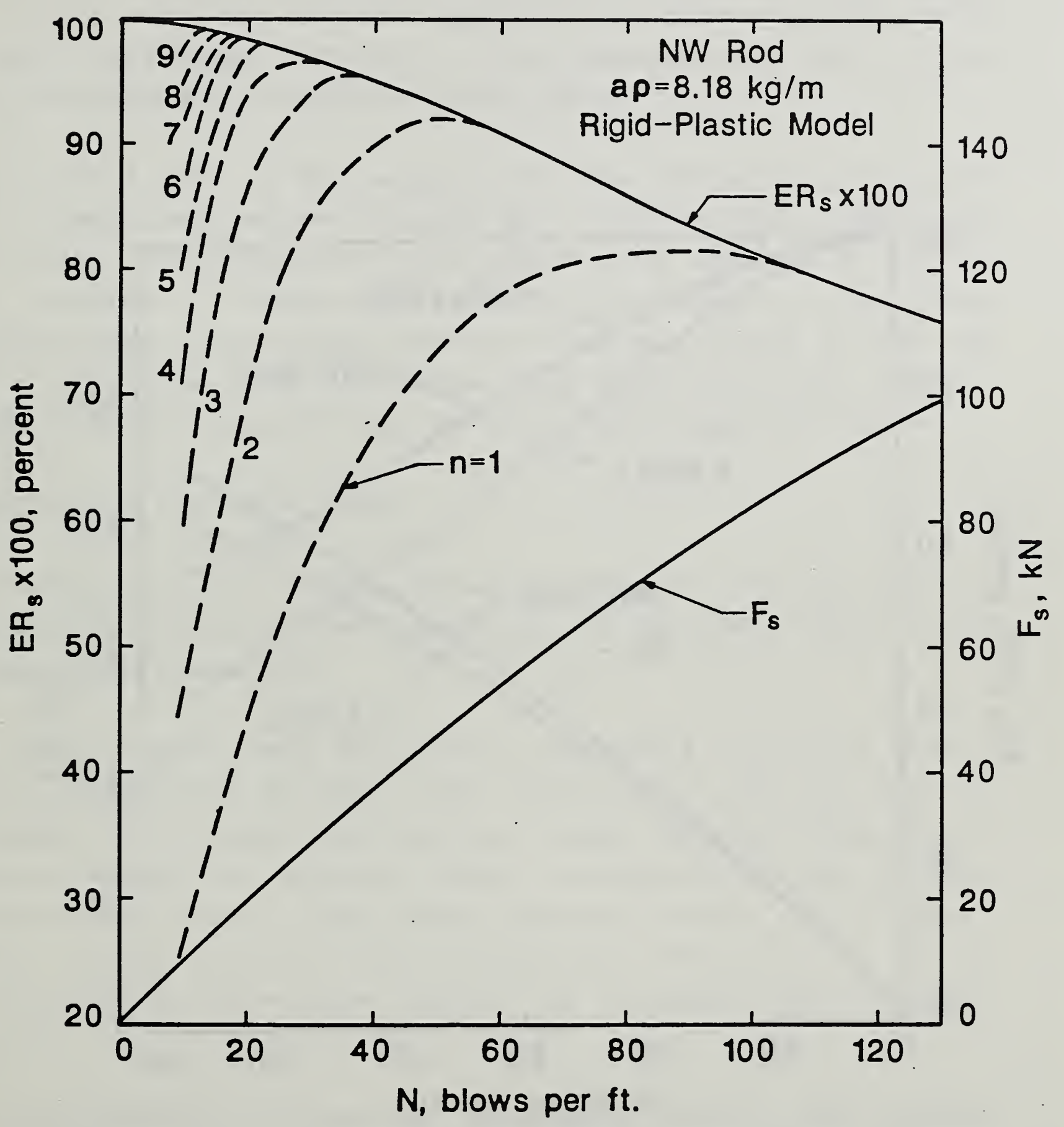

Figure 3: Energy Fraction Used For Soil Penetration as a Function of Blow Count Calculated For a Rigid Plastic Soil Resistance Function and an NW rod (no damping). 


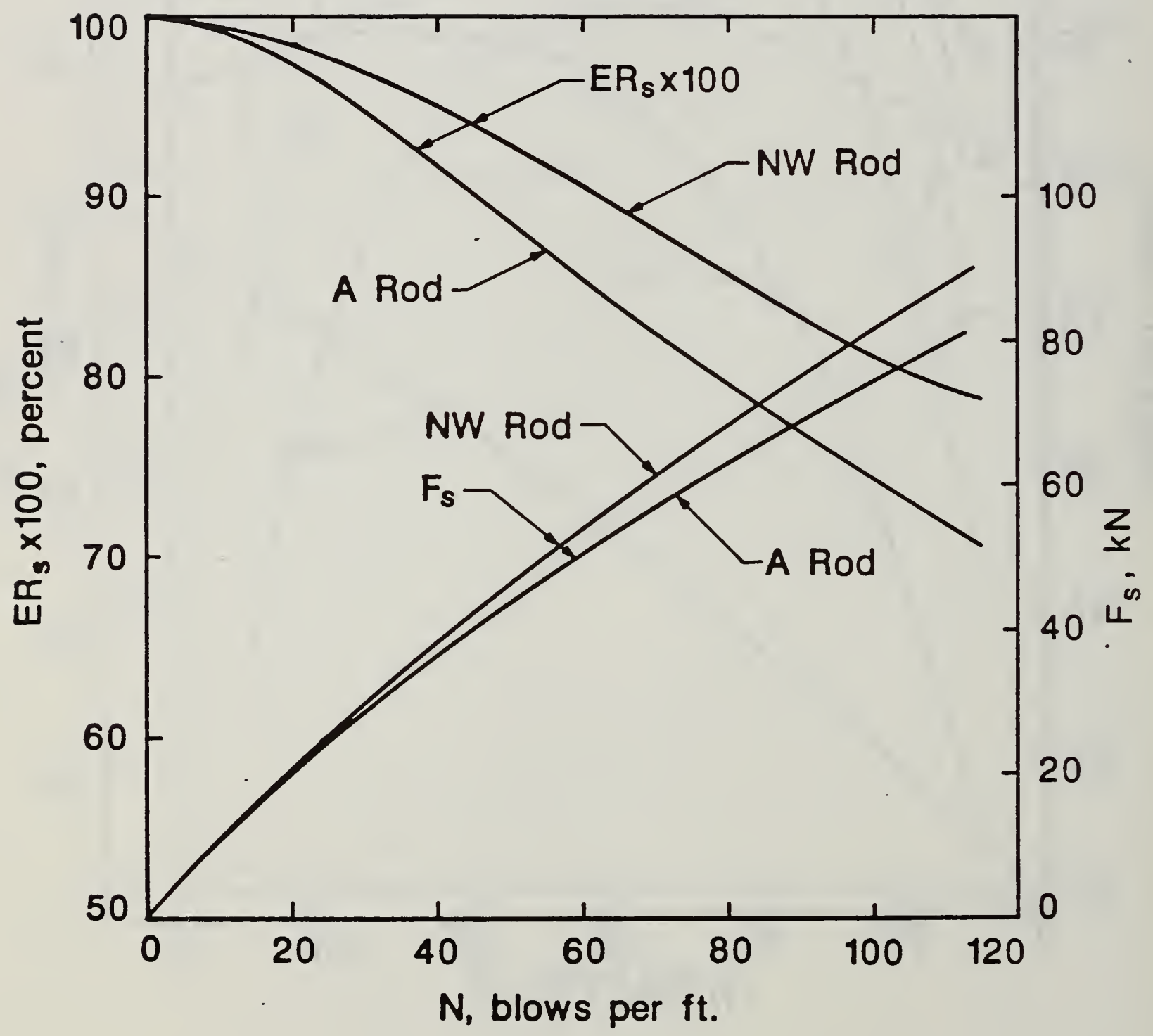

Figure 4: Effect of Drill Rod Size on the Energy Fraction Used for Penetration and the Soil Resistance. 
utilized in the first penetration cycle decreases, but additional energy is utilized in successive penetration cycles. The smaller the blow count, the more penetration cycles are needed to utilize the energy available for soil penetration. Figure 2 also shows the soil resistance force $F_{S}$. It is obvious that this latter force increases with increasing blow counts.

Figure 3 is a plot of $E R_{S}$ versus $N$ for the $N W$ rod, and figure 4 shows a comparison between results for $A$ and $N W$ rods. Note that more energy is utilized for soil penetration when an $\mathrm{NW}$ rod is used. However a comparison of soil resistances $F_{S}$ associated with particular blow counts indicates that the effect of the rod size on the blow count decreases with decreasing blow counts. The effect seems insignificant for blow counts smaller than 40.

LIMITATIONS OF THE MODEL USED

When interpreting the results shown in figures 1 through 4 it is important to recognize the limitations of the model used. Some of these limitations are:

1. A rigid hammer model was used to calculate the force imput. While a comparison of published results in refs.(2) and (4) indicates that results obtained by a more accurate theoretical representation of actual hammer characteristics do not significantly differ from those obtained with a rigid hammer model, force versus time signatures obtained in field measurements (1) are more complex and irregular than those in figure 1 .

2. In the absence of measured attenuation data it was assumed that the stress wave propagating up and down the drill rod, sometimes for large cumulative distances, does not decay as it travels along the rod. Consideration of damping in the drill rod would result in reduced energy utilization for lower blow counts, 
and thus tend to reduce the difference in energy utilization between high and low blow counts. It would also eliminate some of the penetration cycles at lower blow counts.

3. The hammer contact area could differ from the drill rod cross section, resulting in a different force in the rod, and perhaps altering or eliminating the drill rod size effect shown in Fig.4.

4. The rigid-plastic soil penetration model does not consider the energy tied up in elastic soil compression. Since this energy is not independent of soil type, it is difficult to generalize its effect. Figure 5 shows a comparison between the results obtained from a rigid plastic and an elasto plastic soil resistance model for an NW rod. An elastic soil compression of $2 \mathrm{~mm}$ was assumed for all blow counts in the elasto-plastic model. Inherent in this assumption, which is similar to assumptions made in pile analysis, is the concept that soil stiffness is proportional to the blow count. Note that the effect of elastic soil compression increases with increasing blow counts. For large rod lengths the soil could de-compress between successive compression cycles. This would tend to increase the relative effect of soil compression with decreasing blow counts, since some energy would be used for elastic re-compression.

\section{SHORT DRILL RODS}

The effect of the blow count on the energy loss when short drill rods are used is also of interest. This effect is caused by the premature cutoff of the energy transfer from the hammer to the drill rod when the reflected tensile-stress wave reaches the hammer/anvil interface at time $t=2 l / c$, in which $l=$ length of drill rod. If the energy transferred before the return of the tension wave to the hammer equals or exceeds the energy that can be utilized for soil penetration the rod length will have no effect on the blow count. If all of the usable energy is not 


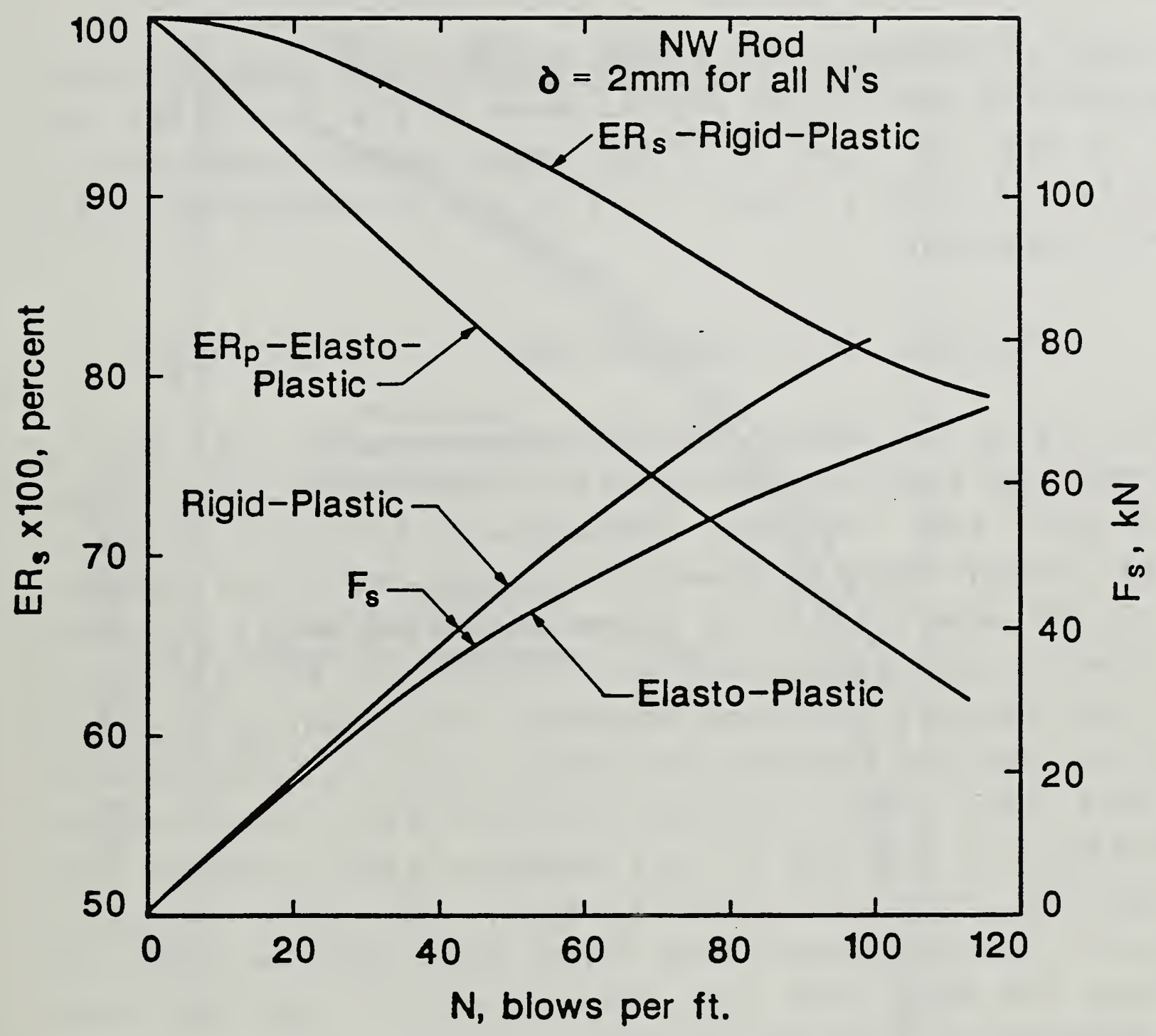

Figure 5: Comparison of Energy Fractions Used For Soil Penetration and Soil Resistance as a Function of Blowcount Calculated for a Rigid-Plastic soil Resistance Function and an Elasto-Plastic Function With an Elastic Soil Displacement of $2 \mathrm{~mm}$ at Penetration. 
transferred, the rod length should be taken into consideration. Since the energy that can be utilized increases with decreasing blow count, the short-rod effect will increase with decreasing blow count.

The effect of the drill rod length and the blow count on energy transmission by short drill rods is shown in Fig. 6. It has been shown (4) that the fraction of the impact energy transmitted to the drill rod during time $t=2 l / c$ can be calculated by the following equation:

$$
E_{r S} / E_{r l}=1-\exp \left(-4 M_{r} / M_{h}\right)
$$

in which $E_{r s}$ is the energy transfered to the short rod, $E_{r l}$ is the energy that would be transfered to a long drill rod, $M_{r}=a l \rho=$ mass of drill rod. Equation (14) accounts for the fraction of the total energy which is transmitted to the drill rod. However part of the energy that is not transmitted would not have contributed to sampler penetration. In Fig. 6, Eq. (14) for an NW rod is compared with the fraction of the energy that can actually be used for various blow counts, which is transmitted by the short rod. This energy fraction was calculated by substituting $2 / / \mathrm{c}$ for $t(n)$ in Eq. 8 whenever $2 l / c$ is smaller than $t(n)$, and dividing the result by Eq.8. Note that the energy fraction is plotted against blow counts that would have resulted if a long rod were used (the actual result of the unutilized energy would be to increase the short-rod blow count for the same soil resistance). It can be seen from Fig. 6 that the energy loss associated with the short-rod effect is less than that predicted when total energy, rather than usable energy is considered and that the energy loss decreases with an icrease in blow count. 
PERCENT OF LONG-ROD ENERGY

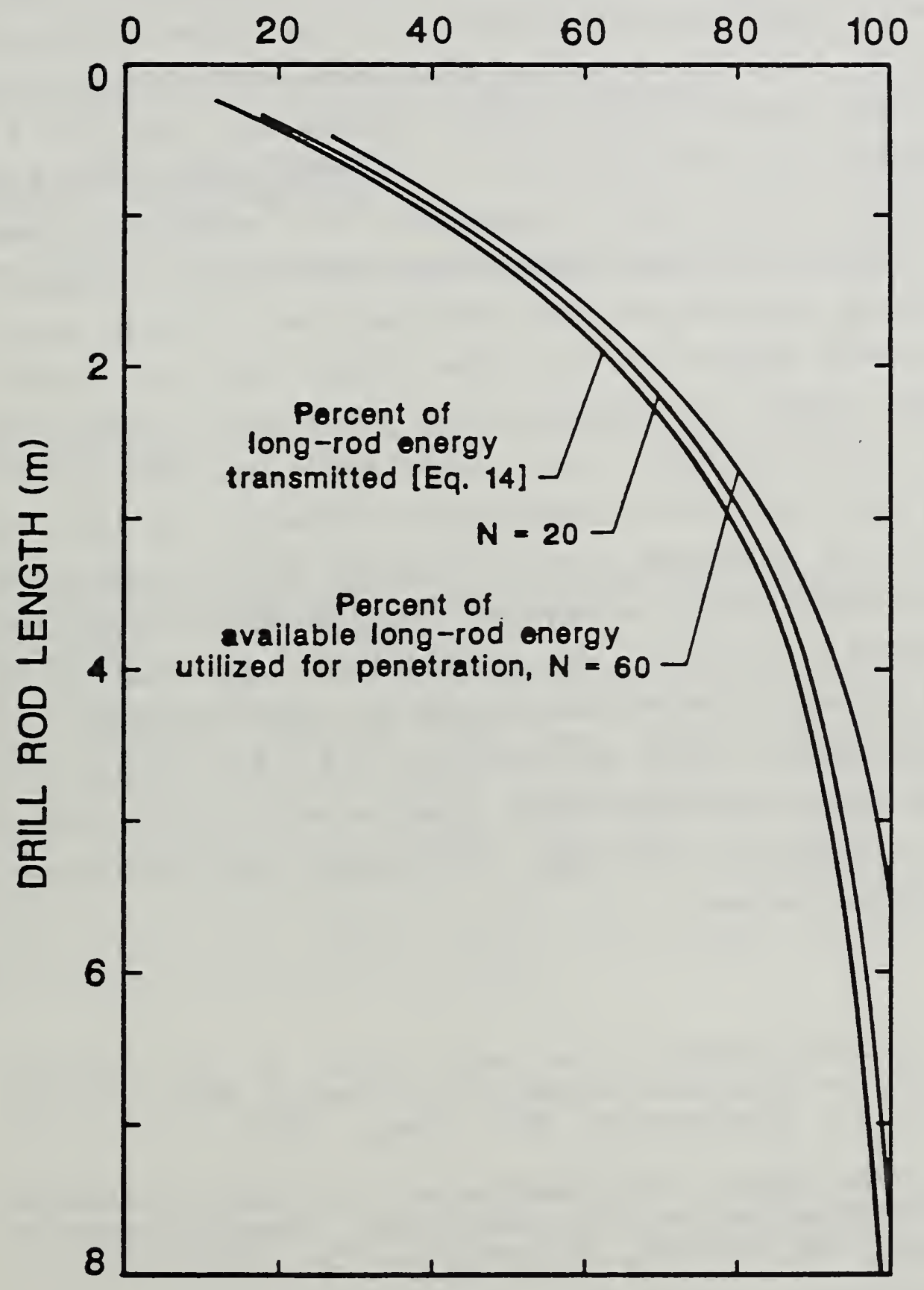

Figure 6: Effect of Drill Rod Length on Energy Transmission 
The energy transfer during sampler penetration in the SPT is studied using a closed-form solution for a rigid-hammer model and a rigid-plastic soil resistance function. It is shown that the energy utilized for soil penetration decreases with increasing blow counts, and that several penetration cycles are required to transfer the energy at low blow counts. It is also shown that the energy utilization for an $\mathrm{NW}$ rod is somewhat more efficient than that for an A rod, but that more penetration cycles are required to transfer the energy from an NW rod and that the rod size would not have a significant effect on the blow count for blow counts less than 40. The energy utilization has also been determined for one particular elasto-plastic soil resistance function and an NW rod. Damping has not been considered because of lack of available data. It is reasoned that in actual field conditions the energy transfer efficiency is reduced for low blow counts and some of the penetration cycles are eliminated. The effect of energy loss caused by using short drill rods is also examined. It is shown that the energy loss associated with the short-rod effect is less than that predicted when total energy, rather than usable energy is considered and that the energy loss decreases with an icrease in blow count.

\section{REFERENCES}

(1) Kovacs, W. D., Salomone, L. A. and Yokel, F. Y., "Energy Measurement in the Standard Penetration Test," NBS Building Science Series 135, Washington, D.C., Aug., 1981.

(2) Palacios, A., "The Theory and Measurement of Energy Transfer During Standard Penetration Test Sampling," thesis presented to the University of Florida, Gainsville, FL., 1977.

(3) Timoshenko, S. and Goodier, T. N., Theory of Elasticity, 3 rd ed., Chapter 14, Sections 168 and 169, McGraw-Hill Publishing Co., Inc., New York, NY, 1970, pp. 496 and 499.

(4) Yokel, F. Y., "Energy Transfer in the Standard Penetration Test, Journal of the Geotechnical Engineering Division, ASCE, Vol. 108, No. GT9, Sept., 1982, pp. 1197-1202. 
1. PUBLICATION OR REPORT NO. NBSIR $88-3765$
2. Performing Organ. Report No. 3. Publication Date

JULY 1988

4. TITLE AND SUBTITLE

Effect of Blow Count on Energy Transfer in the SPT

5. AUTHOR(S)

Felix Y. Yoke1

6. PERFORMING ORGANIZATION (If joint or other than NBS, see instructions)

7. Contract/Grant No.

NATIONAL BUREAU OF STANDARDS

U.S. DEPARTMENT OF COMMERCE

GAITHERSBURG, MD 20899

9. SPONSORING ORGANIZATION NAME AND COMPLETE ADDRESS (Street, City, State, ZIP)

8. Type of Report \& Period Covered

10. SUPPLEMENTARY NOTES

Document describes a computer program; SF-185, FIPS Software Summary, is attached.

11. ABSTRACT (A 200-word or less factual summary of most significant information. If document includes a significant bibliography or literature survey, mention it here)

A rigid-hammer model is used to investigate the effect of the blow count in Standard Penetration Tests on the energy transmission characteristics of the tests. It is shown that the percentage of the impact energy used to advance the sampler decreases with an increase in blow count and could increase somewhat with increasing drill rod size, and that for low blow counts several penetration cycles are required to transmit the energy to the sampler. The effect of the blow count on the energy loss associated with short drill rod lengths is also investigated. It is shown that the energy loss associated with the short-rod effect is less than that predicted when total energy rather than useable energy is considered, and that the energy loss decreases with an increase in blow count.

12. KEY WORDS (Six to twelve entries; alphabetical order; capitalize only proper names; and separate key words by semicolons) boring; energy transfer; field tests; in-situ tests; soil-sampling;

Standard Penetration Test; wave equation

13. AVAILABILITY

XX] Unlimited

For Official Distribution. Do Not Release to NTIS

Order From Superintendent of Documents, U.S. Government Printing Office, Washington, D.C. 20402.

X] Order From National Technical Information Service (NTIS), Springfield, VA. 22161
14. NO. OF

PRINTED PAGES

15. Price

$\$ 9.95$ 

